\title{
PROPERTIES OF MODIFIED CARBOXYMETHYL CELLULOSE PREPARED BY LYOPHILISATION
}

\author{
Karolína Borůvková, Jakub Wiener
}

Technical University of Liberec, Faculty of Textile Engineering, Studentská 2, 46117 Liberec, Czech Republic

E-mail: Boruvkova.K@seznam.cz; jakub.wiener@tul.cz

\begin{abstract}
:
This study deals with the change of selected properties of samples of modified carboxymethyl cellulose after freeze drying. The investigated properties were changes in thickness, permeability, water sorption, thermal area resistance and thermal absorbing capacity. The prepared materials were evaluated by scanning electron microscopy. The product of presented technology has large internal surface, high wettability and biodegradability. It is nontoxic with high potential in biological applications.
\end{abstract}

\section{Keywords:}

Carboxymethyl cellulose, lyophilisation, sorption, permeability, thermal properties

\section{Introduction}

Carboxymethyl cellulose $(\mathrm{CMC})$ is a cellulose derivative with carboxymethyl groups $(-\mathrm{CH} 2-\mathrm{COOH})$ bound to some of the hydroxyl groups of the glucopyranose monomers that make up the cellulose backbone. CMC is prepared in two steps: the first step is based on the preparation of alkali cellulose by reaction with sodium hydroxide. Carboxymethylation is followed by an etherification using chloroacetic acid or its sodium salt. The aim is to convert hydroxyl groups in carboxymethyl groups $[1,2]$. CMC has many desirable applications such as coating, formation of emulsions and suspensions, and water retention. Therefore, it is used in many applications such as medicine, food, paper making, printing and dyeing. CMC is used as a protective colloid, thickeners and dispersions in aqueous solvents [3]. Lyophilisation (freeze drying) is a dehydration process typically used to preserve perishable materials, or to make materials more suitable for the transport, for example, to improve the stability of labile drugs. Lyophilisation of the material takes place by freezing of the material and then reducing the surrounding pressure, allowing the frozen water in the material to sublimate directly from solid phase to gas phase [4].

\section{Experimental methods}

- $\quad$ Lyophilisation (freeze drying): Freeze dryer is a device operating on the principle of vacuum freeze-drying. For this study, a laboratory freeze dryer Christ, type Epsilon $2-6 D$ freezer shelves with a total area of $0.27 \mathrm{~m}^{2}$ was used.

- Electron microscopy: Electron microscopy was performed on the device Tescan-Vega. All samples were covered with a layer of gold before scanning.

- $\quad$ Permeability: Permeability was performed by FX 3300 Air Permeability Tester III from TexTest company. The entire test procedure was in accordance with EN/ISO 9237 (used pressure $100 \mathrm{~Pa}$ ).
- Water sorption: Measurements consisted in immersing samples of approximately $0.2 \mathrm{~g}$ in water. Samples were immersed in water over a defined time. Samples were weighed dry before soaking and then after soaking. The weighing was done on analytical balances.

- Measuring of thickness: Measurement was performed on device Uni-thickness-meter (Computex) with an area of jaw $20 \mathrm{~mm}^{2}$ and pressure of $1 \mathrm{kPa}$.

- Measuring of thermal absorbing capacity and thermal area resistance: Measurement was performed on the device Alambeta with a pressure of $200 \mathrm{~Pa}$.

\section{Materials}

- Sample no. 1: Nonwoven carboxymethyl cellulose fabric (pH 7, DS 0.22).

- Sample no. 2: Nonwoven carboxymethyl cellulose fabric (pH 6.6, DS 0.35).

\section{Results}

Two materials of nonwoven fabrics that have been modified and tested were used in this study. Both textiles are from CMC and have a neutral $\mathrm{pH}$ (the difference between them is in the degree of substitution). Both the samples were immersed in distilled water for a defined time before lyophilisation. Lyophilisation process took 48 hours. Basic (untreated) samples have been tested and compared with freeze-dried samples.

From Figures 1 and 2, it can be seen that samples after lyophilisation obtained soft and a full appearance. Samples are soft to touch and have a warm feel.

In Figure 3, the second graph shows that sample 2a that had the worst absorption of water has the best absorption of sodium 


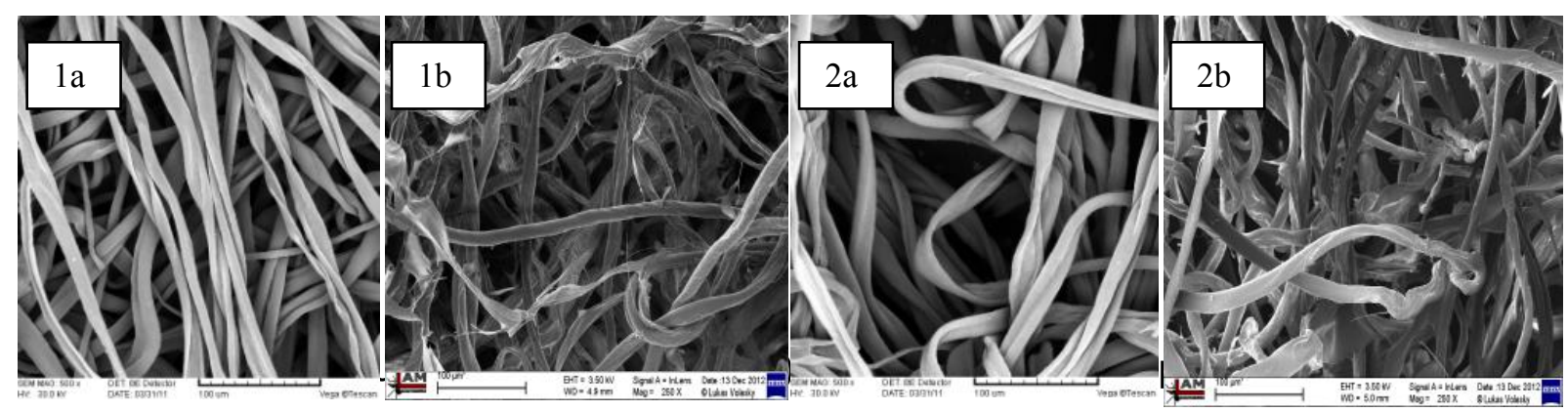

Figure 1. Pictures of basic samples (a) and freeze-dried samples (b) made by SEM.
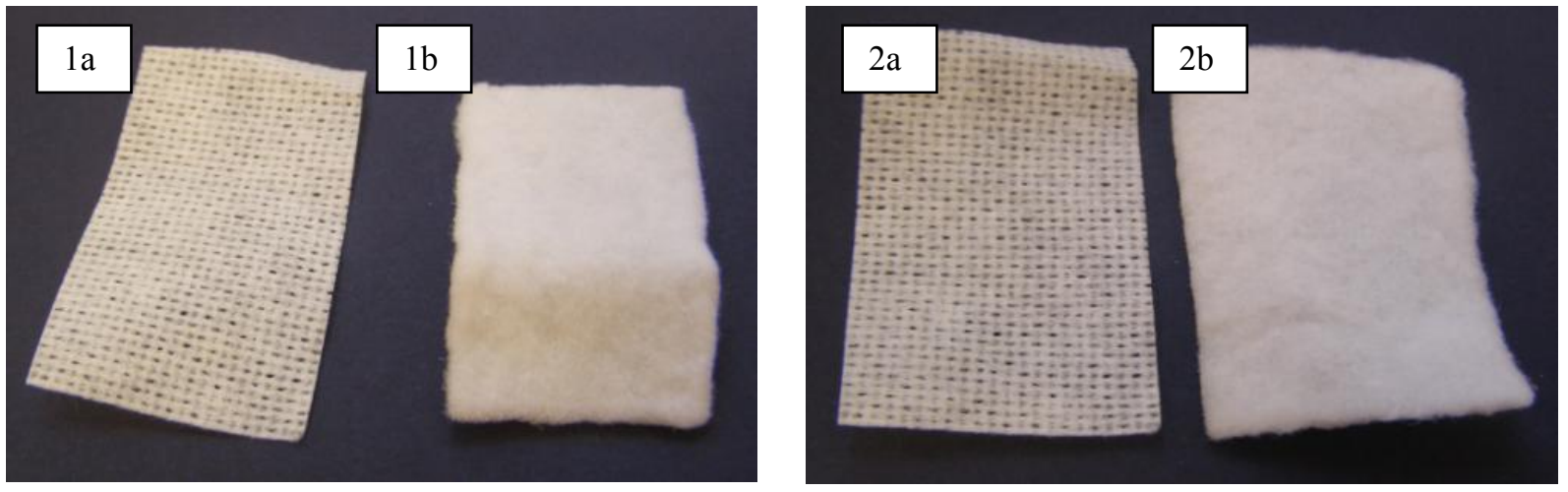

Figure 2. Pictures of basic samples (a) and freeze-dried samples (b).
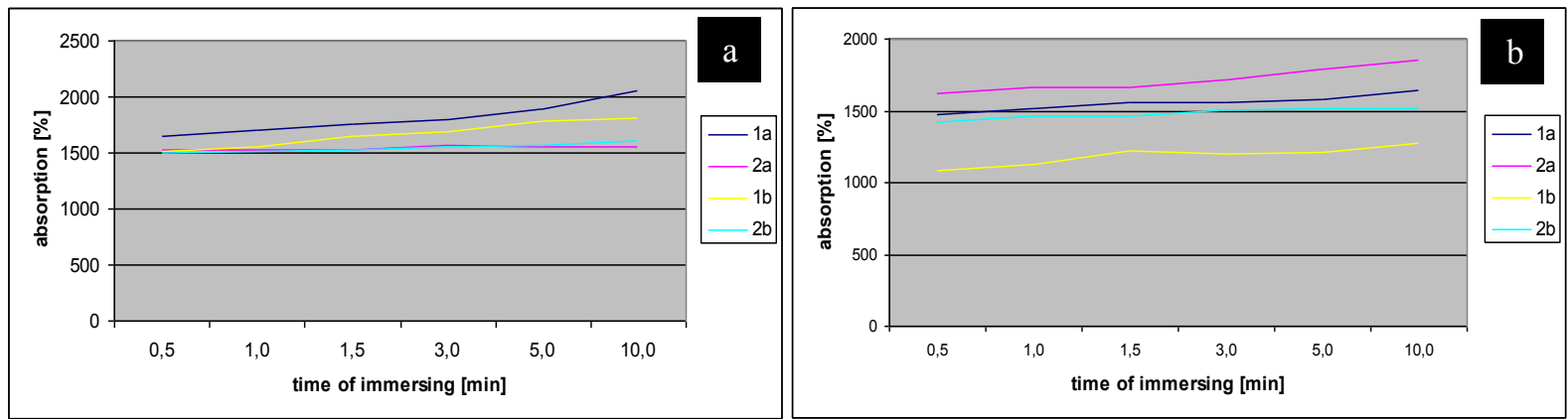

Figure 3. (a) Water absorption and (b) absorption of $0.9 \%$ sodium chloride (saline).

hydroxide. All samples immersed with solution of sodium hydroxide have opposite values compared with absorption of water.

The values of permeability for samples $1 \mathrm{a}, 1 \mathrm{~b}$ and $2 \mathrm{a}$ are almost the same, the only difference is in sample $2 b$ that has a value of permeability approximately halved. All samples show values of permeability in comfortable standards (Figure 4).

In the case of high value of thermal absorbing capacity, the material has a touch cold feel and conversely if this value is low, the material has a touch warm feel. The higher value of the resistance of the textile means that the material is able to dissipate less heat. That shows a good ability of material to keep the warmth. 
obtained a soft and warm touch. Permeability of samples after lyophilisation slightly decreases, but this lower value is still sufficient for comfort. Absorption of both tested samples is high. Lyophilisation does not significantly affect the sorption. As shown in Table 1, both the tested samples after lyophilisation have lower value of thermal absorbing capacity and higher value of area resistance to retain the heat than the samples that were not freeze-dried. It means that samples after lyophilisation have a touch warm feel and they can better keep the warmth.

\section{Summary}

This work dealt with the preparation and testing of samples of modified CMC, which were subsequently lyophilised. Freezedried samples obtained better thermal insulation properties, noticeably thicker and softer feel. Both tested materials have a high permeability in the dry state and high capacity to absorb and retain water. The above-mentioned properties make this final product for use in technical and biological applications.

\section{Acknowledgements}

This paper is supported by TAČR ALFA TA01010244 (HMEDMAT), Czech Republic.

Table 1. Thickness and thermal properties.

\begin{tabular}{|c|c|c|c|}
\hline Samples & Thickness & $\begin{array}{l}\text { Thermal } \\
\text { absorbing } \\
\text { capacity }\end{array}$ & $\begin{array}{c}\text { Area } \\
\text { resistant } \\
\text { to heat }\end{array}$ \\
\hline & $h[\mathrm{~mm}]$ & $b\left[\mathrm{~W} \times \mathrm{m}^{-2} \times \mathrm{s}^{1 / 2} \times \mathrm{K}^{-1}\right]$ & $R\left[\mathrm{~W}^{-1} \times \mathrm{K} \times \mathrm{m}^{2}\right]$ \\
\hline $1 a$ & 0.51 & 85.7 & 0.0276 \\
\hline $1 b$ & 2.66 & 64.1 & 0.0569 \\
\hline $2 a$ & 0.49 & 91.2 & 0.0273 \\
\hline $2 b$ & 2.44 & 64.3 & 0.0575 \\
\hline
\end{tabular}

\section{References}

[1] Heinze, T.; Pfeiffer, K.: Studies on the synthesis and characterization of carboxymethylcellulose, Angewandte Makromolekulare Chemie, Vol. 266, pp. 37-45, 1999.

[2] Fang, Y.; Gang, L.; Yan-Gang, H.; Feng-Xia, R.; Gui-Xiang, $W .:$ Synthesis, characterization, and applied properties of carboxymethyl cellulose and polyacrylamide graft copolymer; Carbohydrate Polymers, 2009.

[3] Borůvková, K.; Wiener, J.: Water absorption in carboxymethyl cellulose, AUTEX Research Journal, Vol. 11, 2011

[4] Adel, A. M.; Abou-Youssef, H.; El-Gendy, A. A.; Nada, A. M.: Carboxymethylated cellulose hydrogel - sorption behavior and characterization, Nature and Science, Vol. 8, 2010. 